\title{
Corrosion of carbon-alloyed iron aluminides
}

\author{
M SEN, R BALASUBRAMANIAM* and A V RAMESH KUMAR ${ }^{\dagger}$ \\ Department of Materials and Metallurgical Engineering, Indian Institute of Technology, Kanpur 208 016, India \\ ${ }^{\dagger}$ Defence Materials Stores and Research Development Establishment, Kanpur 208 013, India
}

MS received 22 May 2000; revised 17 August 2000

\begin{abstract}
The corrosion behaviour of two carbon-alloyed intermetallics of composition Fe-28-1Al-2·1C and Fe-27.5Al-3.7C has been studied and compared with that of binary intermetallics. Potentiodynamic polarization studies indicated that the intermetallics exhibited active-passive behaviour in an acidic solution of $\mathbf{p H}=1$, whereas they exhibited stable passivity in a buffer solution of pH 8.4. Corrosion rates were also obtained by immersion testing. The variation of corrosion rate as a function of time was similar for both the intermetallics. The variation in corrosion rate as a function of time has been explained based on the observed potentiodynamic polarization behaviour. Scanning electron microscopy of corroded surfaces indicated that the carbon-alloyed intermetallics were susceptible to galvanic corrosion, due to the presence of carbides.
\end{abstract}

Keywords. Corrosion; iron aluminides; $\mathrm{Fe}_{3} \mathrm{Al}$; potentiodynamic polarization.

\section{Introduction}

Ordered intermetallic alloys based on iron aluminides of composition $\mathrm{Fe}_{3} \mathrm{Al}$ and $\mathrm{FeAl}$ are being considered for high temperature structural applications. Although these alloys exhibit poor room temperature ductility and low fracture toughness, significant improvement in these respects can be achieved by alloying additions and process control. Most of the available literature deals with iron aluminide compositions with very low $(<0.01 \mathrm{wt} \%)$ carbon contents because carbon causes significant reduction in ductility. Recently, Baligdad et al (1997a) reported that addition of carbon in the range of 0.14 to $0.50 \mathrm{wt} \%$ significantly increased the room temperature strength of $\mathrm{Fe}$ $16 \mathrm{wt} \%$ (28 at\%) $\mathrm{Al}$ alloys. These alloys also exhibited relatively significant room temperature ductilities, which was attributed to irreversible trapping of hydrogen at $\mathrm{Fe}_{3} \mathrm{AlC}$ carbide-matrix interfaces (Baligdad et al 1997b). The trapping of hydrogen at these interfaces has been confirmed by hydrogen diffusivity measurements in carbonalloyed iron aluminides (Sen and Balasubramaniam 2000). Moreover, the carbon-alloyed iron aluminides were stronger and this increase in room temperature yield strength was attributed to solid solution strengthening by the interstitial carbon, as well as precipitation hardening due to the presence of $\mathrm{Fe}_{3} \mathrm{AlC}$ precipitates (Baligdad et al 1997b). The aim of the present study is to understand the ambient temperature corrosion behaviour of these intermetallics.

\footnotetext{
*Author for correspondence
}

\section{Experimental}

The carbon-alloyed iron aluminides were obtained in the form of rolled metal strips (Baligdad et al 1994) from the Defence Metallurgical Research Laboratory, Hyderabad. Their composition (in at\%) were $\mathrm{Fe}-28 \cdot 1 \mathrm{Al}-2 \cdot 1 \mathrm{C}$ and $\mathrm{Fe}-27 \cdot 5 \mathrm{Al}-3 \cdot 7 \mathrm{C}$. In order to understand the polarization behaviour of these intermetallics, square sections of $1 \mathrm{~cm}$ side, were sectioned and connected to a conductive wire. The specimens were mounted in a cold-setting epoxy. The specimen surfaces were polished to 600 grit surface finish and were properly cleaned with acetone prior to polarization experiments. Polarization experiments were performed in an electrochemical polarization cell using a potentiostat (EG \& G 273 model) interfaced to a personal computer. A platinum foil of $1 \mathrm{~cm}^{2}$ area was used as the counter electrode. A $0.05 \mathrm{~mol} / 1 \mathrm{H}_{2} \mathrm{SO}_{4}$ solution of $\mathrm{pH}=1$, and a buffer solution $\left(0 \cdot 15 \mathrm{~N} \mathrm{H}_{3} \mathrm{BO}_{3}+0 \cdot 15 \mathrm{~N}\right.$ $\mathrm{Na}_{2} \mathrm{~B}_{4} \mathrm{O}_{7}-10 \mathrm{H}_{2} \mathrm{O}$ ) of $\mathrm{pH}=8.44$ were the electrolytes used in the present study. Before each polarization experiment, the specimen was immersed in the electrolyte and the free corrosion potential (FCP) was monitored as a function of time. The potential was monitored continuously using standard calomel electrode (SCE) attached to the luggin capillary. All potentials referred in this paper are with respect to SCE. The FCP stabilized usually in a short time. Once the steady state FCP were obtained, the potentiodynamic polarization experiment was performed at a scan rate of $1 \mathrm{mV} / \mathrm{sec}$. The potential was scanned from active to noble direction. The temperature of the polarization cell was not controlled and all experiments were performed at ambient temperature $\left(25^{\circ} \mathrm{C}\right)$. 
The corrosion rates of the alloys were also determined in the $0.05 \mathrm{~mol} / \mathrm{H} \mathrm{H}_{2} \mathrm{SO}_{4}$ solution by constant immersion testing. Two types of immersion tests were performed. The first type was a relatively long term testing for a total period of 8 days with weight losses being measured after every $12 \mathrm{~h}$. In the second type, experiments were performed for a total duration of only $24 \mathrm{~h}$ with weight losses measured at $30 \mathrm{~min}$ intervals. The weight loss data previously obtained by $\mathrm{Babu}$ et al (2000) for $\mathrm{Fe}-25 \mathrm{Al}$ and $\mathrm{Fe}-28 \mathrm{Al}$ intermetallics in the same solution have been compared.

\section{Results and discussion}

\subsection{Potentiodynamic polarization}

The potentiodynamic polarization curves obtained in the acidic medium for the carbon-alloyed intermetallics, along with that for the $\mathrm{Fe}-28 \mathrm{Al}$ intermetallic, are presented in figure 1, while the results obtained in the buffer solution are presented in figure 2. Both the carbonalloyed intermetallics exhibited active-passive behaviour in the acidic solution, in that there was a region where the current density was lowered on polarizing past the zero

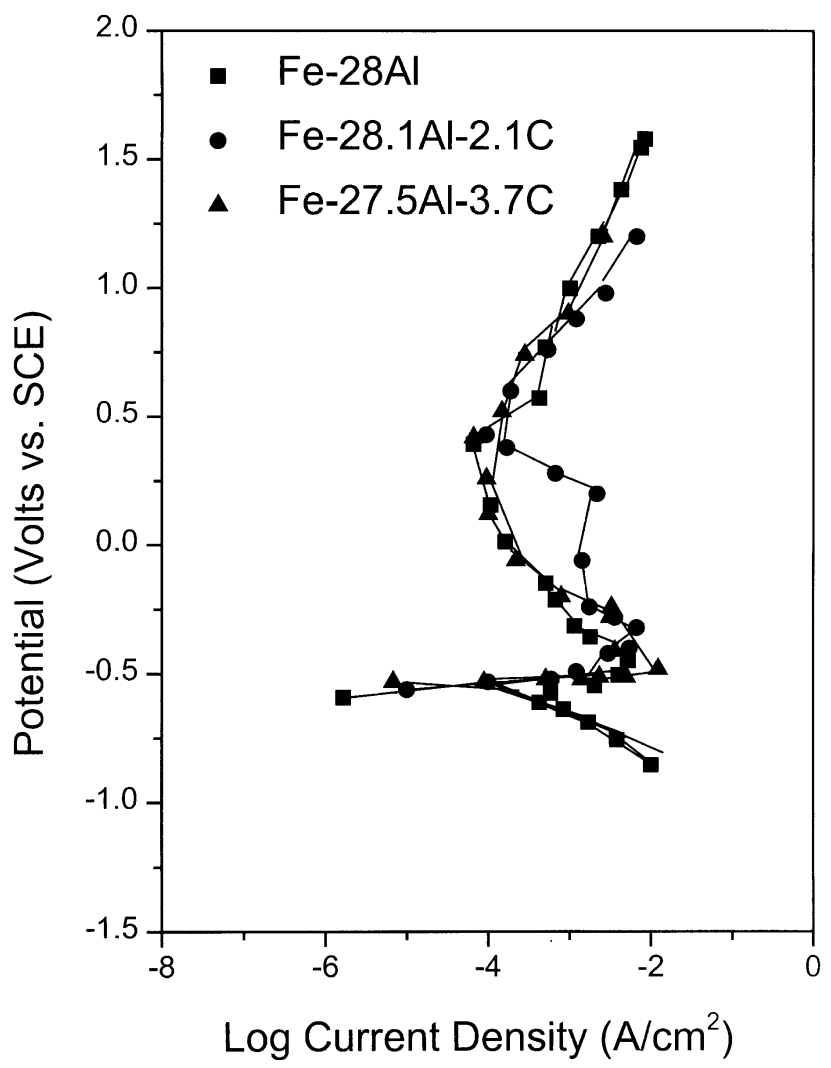

Figure 1. Potentiodynamic polarization diagrams obtained in $0.05 \mathrm{~mol} / 1 \mathrm{H}_{2} \mathrm{SO}_{4}$ solution of $\mathrm{pH}=1$, at a scan rate of $1 \mathrm{mV} / \mathrm{s}$. The intermetallics exhibited active-passive behaviour. The data for $\mathrm{Fe}-28 \mathrm{Al}$ is from Babu et al (2000). current potential. The passivity parameters from these plots are tabulated in table 1 . In the buffer solution, the nature of the polarization curves indicated that both the carbon-alloyed intermetallics passivated readily on immersion. The passive current densities $\left(i_{\text {pass }}\right)$ for both the intermetallics were lower in the buffer solution, when compared to those in the acidic solution.

In the acidic solution, the critical current density for passivation $\left(i_{\text {crit }}\right)$ was lower for $\mathrm{Fe}-28 \cdot 1 \mathrm{Al}-2 \cdot 1 \mathrm{C}$ when compared to $\mathrm{Fe}-27 \cdot 5 \mathrm{Al}-3 \cdot 7 \mathrm{C}$. Moreover, the $i_{\text {crit }}$ for the binary $\mathrm{Fe}-28 \mathrm{Al}$ was lower than those of both these intermetallics, thereby indicating that the $i_{\text {crit }}$ increased with increasing carbon addition. As regards the passive region in the $0.05 \mathrm{~mol} / \mathrm{H} \mathrm{H}_{2} \mathrm{SO}_{4}$ solution, for the $\mathrm{Fe}-28 \mathrm{Al}$ intermetallic (without carbon addition), the passive current density $\left(i_{\text {pass }}\right.$ ) was equal to $7.4 \times 10^{-5} \mathrm{~A} / \mathrm{cm}^{2}$ and the potential for primary passivation $\left(E_{\text {pass }}\right)$ was $0.37 \mathrm{~V}$ (Babu et al 2000). In the same solution, the measured $i_{\text {pass }}$ were $8.3 \times 10^{-5} \mathrm{~A} / \mathrm{cm}^{2}$ and $7.2 \times 10^{-5} \mathrm{~A} / \mathrm{cm}^{2}$ for $\mathrm{Fe}-$ $28 \cdot 1 \mathrm{Al}-2 \cdot 1 \mathrm{C}$ and $\mathrm{Fe}-27 \cdot 5 \mathrm{Al}-3 \cdot 7 \mathrm{C}$, respectively. Moreover, the $E_{\text {pass }}$ were $0.36 \mathrm{~V}$ and $0.41 \mathrm{~V}$ for $\mathrm{Fe}-28 \cdot 1 \mathrm{Al}-$ $2 \cdot 1 \mathrm{C}$ and $\mathrm{Fe}-27 \cdot 5 \mathrm{Al}-3 \cdot 7 \mathrm{C}$, respectively.

The corrosion rates were determined from the active region of the polarization curves (obtained in the acidic

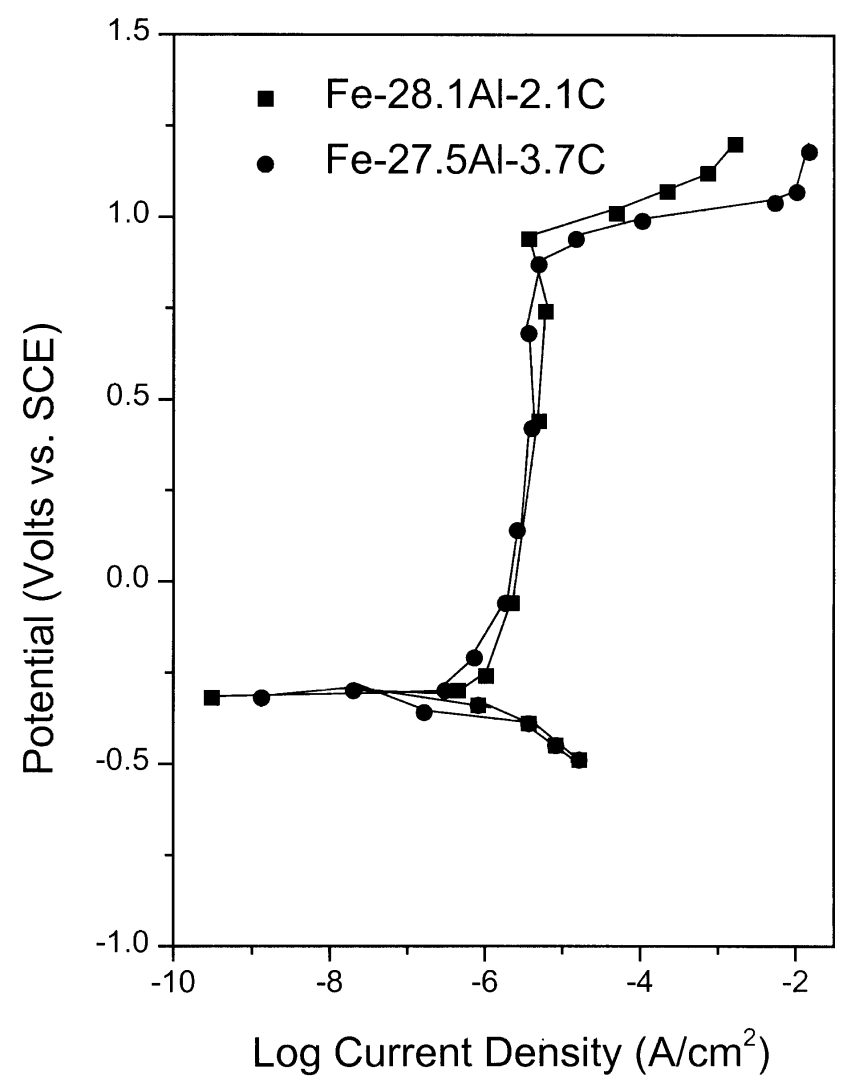

Figure 2. Potentiodynamic polarization diagrams obtained in $0 \cdot 15 \mathrm{~N} \mathrm{H}_{3} \mathrm{BO}_{3}+0 \cdot 15 \mathrm{~N} \mathrm{Na}_{2} \mathrm{~B}_{4} \mathrm{O}_{7} \cdot 10 \mathrm{H}_{2} \mathrm{O}$ solution of $\mathrm{pH}=8 \cdot 44$, at a scan rate of $1 \mathrm{mV} / \mathrm{s}$. The intermetallics exhibited stable passive behaviour. 
Table 1. Parameters determined from the potentiodynamic polarization curves for the carbon-alloyed iron aluminides.

\begin{tabular}{|c|c|c|c|c|c|c|c|c|c|}
\hline Sample & $\begin{array}{c}\beta_{\mathrm{a}} \\
\text { (V/dec.) }\end{array}$ & $\begin{array}{c}\beta_{\mathrm{c}} \\
(\mathrm{V} / \mathrm{dec} .)\end{array}$ & $\begin{array}{l}E_{\text {corr }} \\
(\mathrm{V})\end{array}$ & $\begin{array}{c}i_{\text {corr }} \\
\left(\mathrm{A} / \mathrm{cm}^{2}\right)\end{array}$ & $\begin{array}{c}i_{\text {crit }} \\
\left(\mathrm{A} / \mathrm{cm}^{2}\right)\end{array}$ & $\begin{array}{l}E_{\text {pass }} \\
(\mathrm{V})\end{array}$ & $\begin{array}{c}i_{\text {pass }} \\
\left(\mathrm{A} / \mathrm{cm}^{2}\right)\end{array}$ & $\begin{array}{l}E_{\mathrm{b}} \\
(\mathrm{V})\end{array}$ & Remarks \\
\hline $\begin{array}{c}\mathrm{Fe}-28 \cdot 1 \mathrm{Al}-2 \cdot 1 \mathrm{C} \\
(\mathrm{pH}=8 \cdot 4)\end{array}$ & $0 \cdot 04$ & 0.08 & $-0 \cdot 304$ & $2.00 \times 10^{-7}$ & - & - & $1 \cdot 3 \times 10^{-6}$ & 0.933 & $\begin{array}{l}\text { Stable } \\
\text { passivity }\end{array}$ \\
\hline $\begin{array}{c}\mathrm{Fe}-28 \cdot 1 \mathrm{Al}-2 \cdot 1 \mathrm{C} \\
(\mathrm{pH}=1 \cdot 0)\end{array}$ & $0 \cdot 20$ & $0 \cdot 26$ & -0.537 & $1.54 \times 10^{-5}$ & $6.69 \times 10^{-3}$ & $0 \cdot 36$ & $8.3 \times 10^{-5}$ & $0 \cdot 369$ & $\begin{array}{l}\text { Active- } \\
\text { passive }\end{array}$ \\
\hline $\begin{array}{c}\mathrm{Fe}-27 \cdot 5 \mathrm{Al}-3 \cdot 7 \mathrm{C} \\
(\mathrm{pH}=8 \cdot 4)\end{array}$ & $0 \cdot 04$ & $0 \cdot 12$ & -0.279 & $3.14 \times 10^{-7}$ & - & - & $2 \cdot 8 \times 10^{-6}$ & $0 \cdot 885$ & $\begin{array}{l}\text { Stable } \\
\text { passivity }\end{array}$ \\
\hline $\begin{array}{c}\mathrm{Fe}-27 \cdot 5 \mathrm{Al}-3 \cdot 7 \mathrm{C} \\
(\mathrm{pH}=1 \cdot 0)\end{array}$ & $0 \cdot 24$ & $0 \cdot 27$ & -0.573 & $2.44 \times 10^{-5}$ & $9.86 \times 10^{-3}$ & $0 \cdot 41$ & $7 \cdot 2 \times 10^{-5}$ & $0 \cdot 408$ & $\begin{array}{l}\text { Active- } \\
\text { passive }\end{array}$ \\
\hline
\end{tabular}

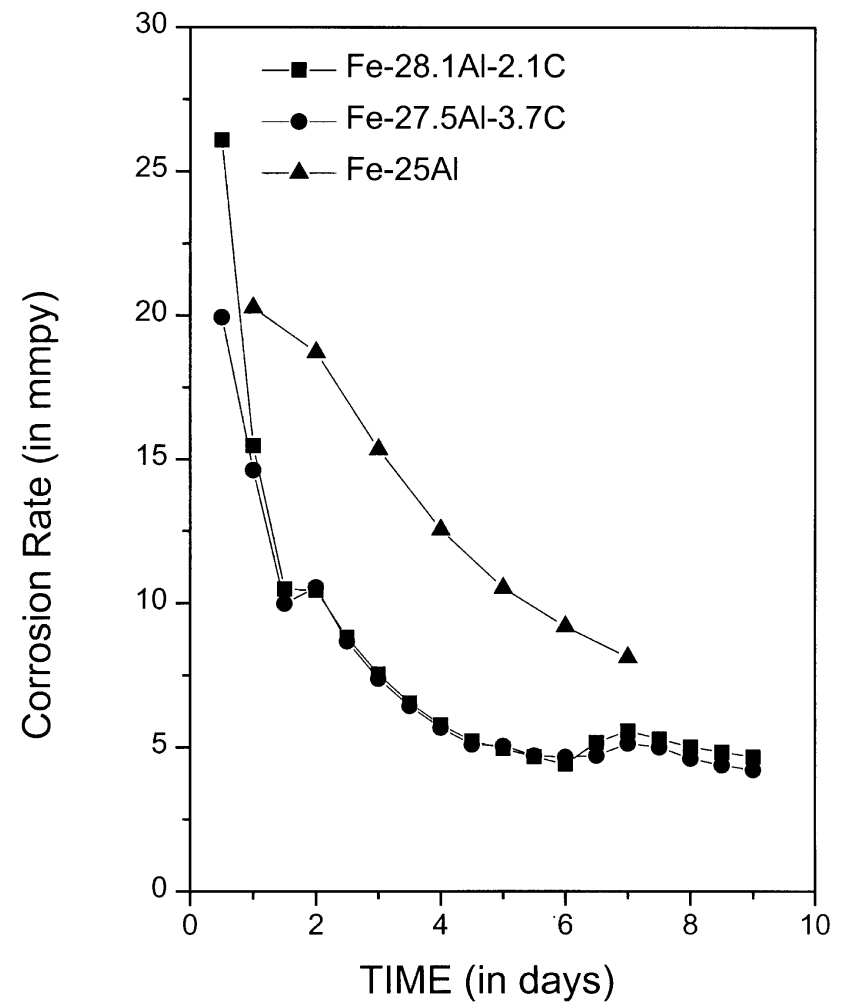

Figure 3. Corrosion rate as a function of time for the intermetallics in $0.05 \mathrm{~mol} / 1 \mathrm{H}_{2} \mathrm{SO}_{4}$ solution. Data were obtained after $24 \mathrm{~h}$ intervals. The data for $\mathrm{Fe}-28 \mathrm{Al}$ is from $\mathrm{Babu}$ et al (2000).

medium) using the Tafel extrapolation method. The corrosion rate in millimeters per year (mmpy) was calculated from the corrosion current by the following relation (Jones 1992),

Corrosion rate $($ in $\mathrm{mmpy})=C . E . I_{\text {corr }} / d . A$,

where, $C$ is the conversion factor $\left(=3.06 \times 10^{5}\right)$ for obtaining rate in units of mmpy, $E$ the equivalent weight of the intermetallic in $\mathrm{g} / \mathrm{mol}, I_{\text {corr }}$ the corrosion current in amp, $d$ the density of the intermetallic in $\mathrm{g} / \mathrm{cc}$ and $A$ the exposed cross section of the intermetallic in $\mathrm{cm}^{2}$. For the carbon-alloyed intermetallics, the values of $E$ and $d$ were estimated as $21.7 \mathrm{~g} / \mathrm{mol}$ and $6.72 \mathrm{~g} / \mathrm{cc}$, respectively. The cross sectional area exposed for the polarization experi-

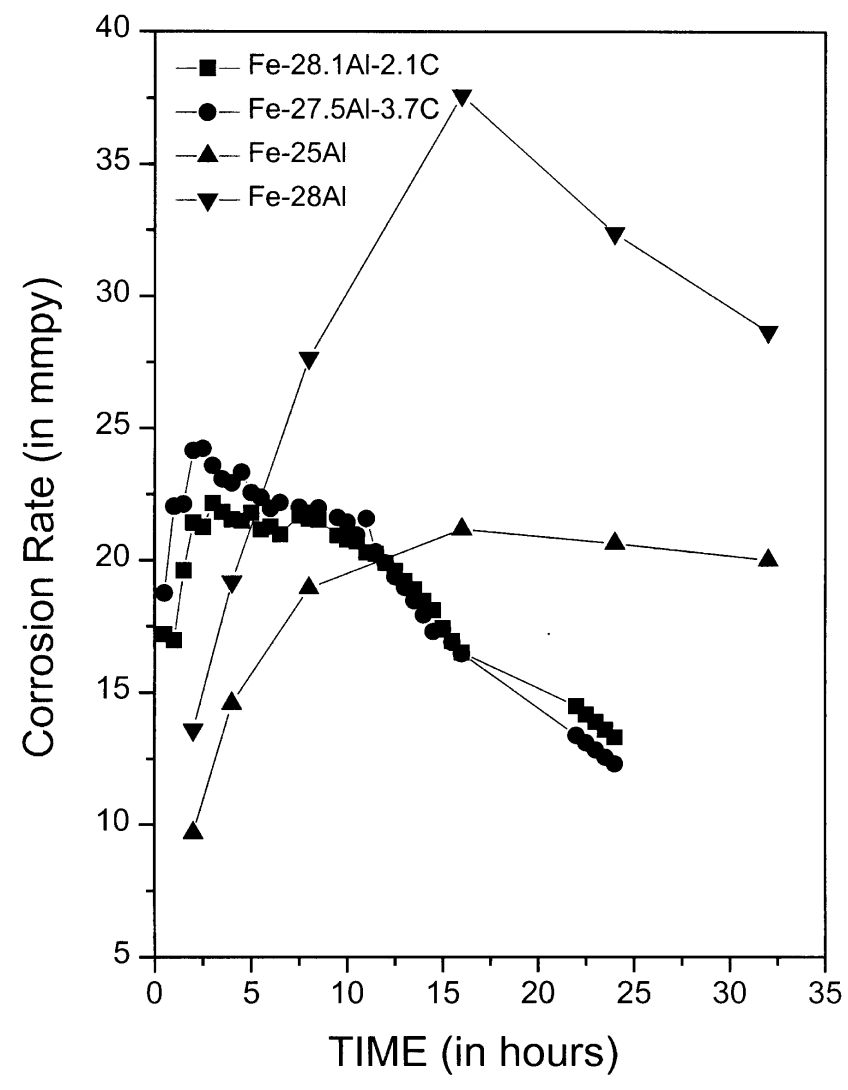

Figure 4. Corrosion rate as a function of time for the intermetallics in $0.05 \mathrm{~mol} / 1 \mathrm{H}_{2} \mathrm{SO}_{4}$ solution. Data were obtained after $0.5 \mathrm{~h}$ intervals. The data for $\mathrm{Fe}-25 \mathrm{Al}$ and $\mathrm{Fe}-28 \mathrm{Al}$ is from Babu et al (2000).

ment was $1 \mathrm{~cm}^{2}$. The corrosion rates in the $0.05 \mathrm{~mol} / 1$ $\mathrm{H}_{2} \mathrm{SO}_{4}$ solution thus obtained were $15 \cdot 1$ mmpy and $24 \cdot 1 \mathrm{mmpy}$ for $\mathrm{Fe}-28 \cdot 1 \mathrm{Al}-2 \cdot 1 \mathrm{C}$ and $\mathrm{Fe}-27 \cdot 5 \mathrm{Al}-3 \cdot 7 \mathrm{C}$, respectively. The corrosion rates of the two alloys are similar and comparable to the corrosion rates determined using direct weight loss measurements by immersion testing, which will be discussed below.

\subsection{Immersion testing}

The weight loss data as a function of time was utilized to obtain the cumulative corrosion rate up to that point of 
time. The corrosion rate as a function of time is presented in figure 3 for both the intermetallics. The rates of corrosion were high initially for both the intermetallics. Thereafter, the corrosion rate decreased and remained nearly constant in the last few days of the experiment. A similar behaviour was also observed for $\mathrm{Fe}-25 \mathrm{Al}$ (Babu et al 2000). In order to understand the high rate of corrosion in the initial stages, short-term immersion tests were carried out for a total duration of $24 \mathrm{~h}$ and the weight loss was measured after every $30 \mathrm{~min}$. The results of these tests are presented in figure 4 for the intermetallics. The corrosion rate increased initially and after attaining a peak value at about $2 \mathrm{~h}$, decreased continuously. Interestingly, the $\mathrm{Fe}-28 \mathrm{Al}$ specimen also exhibited a similar behaviour in that the corrosion rate was maximum after a certain period of immersion and then decreased with time. It is also important to note that the corrosion rates of both the carbon-alloyed intermetallics were comparable to those of $\mathrm{Fe}-25 \mathrm{Al}$ and $\mathrm{Fe}-28 \mathrm{Al}$ (Babu et al 2000).

The observed corrosion rate behaviour (i.e. high corrosion rate in the initial stages) could be due to selective dissolution. Selective dissolution implies either selective dissolution of one phase or selective dissolution from some specific locations in the material. The decrease in corrosion rate on continued immersion indicated that the intermetallics had attained an equilibrium surface layer. This can be explained based on the polarization behaviour. It is reasonable to propose that the critical current density for passivation would be attained due to the high rate of corrosion in the initial stages. The achievement of passivation is confirmed by the decrease in corrosion rate in the later stages, and also by the constant corrosion rate measured in the final stages (figure 3 ). In this regard, the presence of carbide-metal interfaces would accelerate the corrosion process and the critical current density would be attained in a shorter time than for the base intermetallic. This should result in shorter times to achieve the maximum in corrosion rate for the carbon-alloyed intermetallics when compared to the binary intermetallics. This has also been experimentally observed (figure 4). Another possible reason for the decrease in the corrosion rate with time is the decreasing corrodability of the solution with time. This seems unlikely in the present study as the solution $\left(0.05 \mathrm{~mol} / 1 \mathrm{H}_{2} \mathrm{SO}_{4}\right)$ used for immersion testing was relatively strong.

\subsection{Microstructural features}

In order to gain further insights into the microstructural aspects of the corroding surfaces, independent immersion experiments were conducted and the corroded surfaces were observed in a JEOL JSM 840A scanning electron microscope. Both the carbon-alloyed intermetallics exhibited similar microstructural features-a uniform distribution of relatively large $\mathrm{Fe}_{3} \mathrm{AlC}$ carbide precipi- tates in the matrix. A typical microstructure is provided in figure $5 \mathrm{a}$.

The microstructures of both the samples were analyzed for obtaining information on the carbide particle distribution (the carbide particle size and its surface area per unit volume). For this purpose, five photographs of each sample were taken at different places at a magnification of $100 \times$. The volume fraction of the carbide particles and
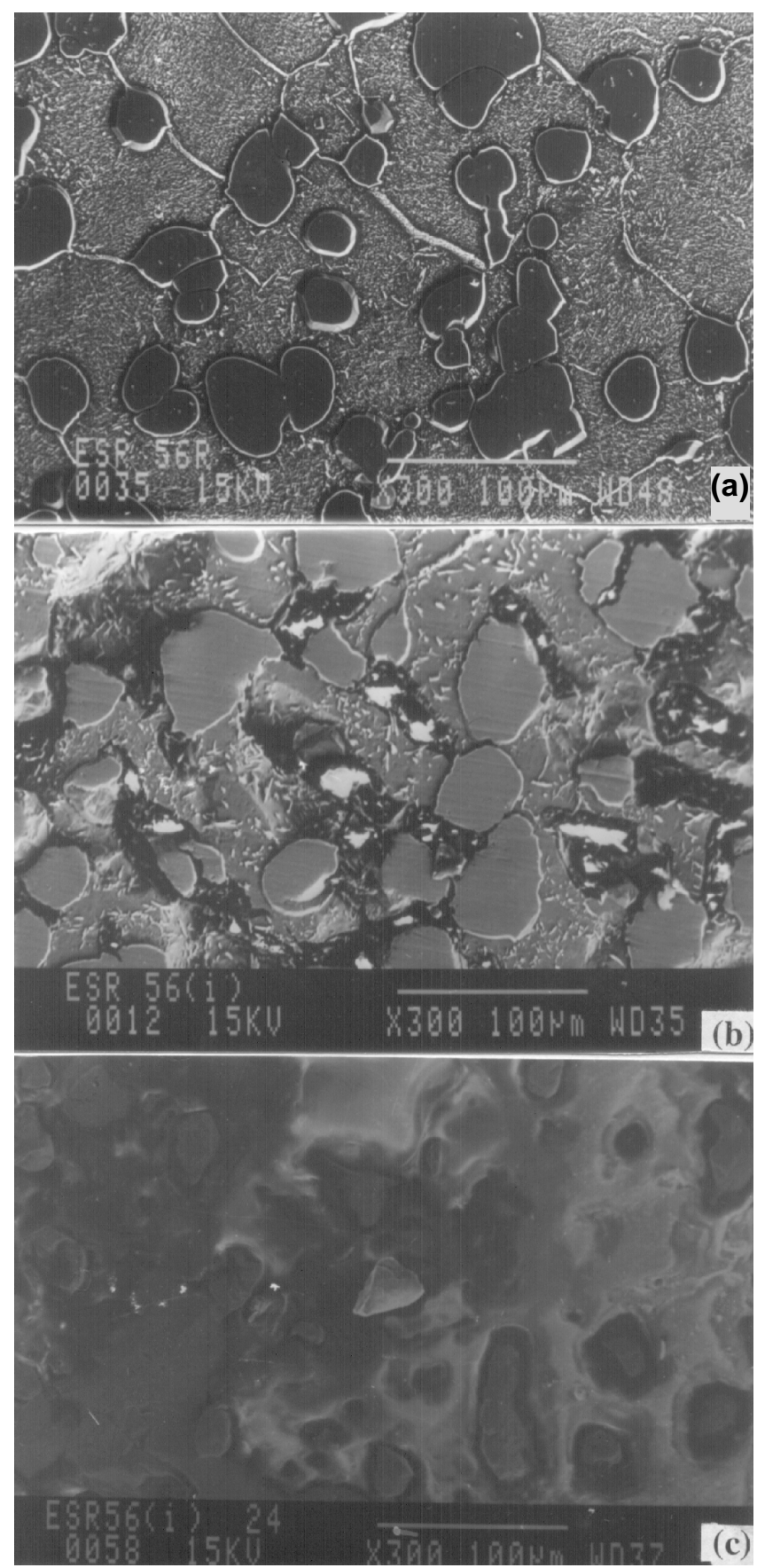

Figure 5. SEM micrograph of $\mathrm{Fe}-28 \cdot 1 \mathrm{Al}-2 \cdot 1 \mathrm{C}$ : (a) basic microstructure, (b) after immersion for $2 \mathrm{~h}$ and (c) after immersion for $24 \mathrm{~h}$ in $0.05 \mathrm{~mol} / 1 \mathrm{H}_{2} \mathrm{SO}_{4}$ solution. 
Table 2. Average diameter, volume fraction and surface area per unit volume of the carbide particles in the $\mathrm{Fe}-28 \cdot 1 \mathrm{Al}-2 \cdot 1 \mathrm{C}$ and $\mathrm{Fe}-27 \cdot 5 \mathrm{Al}-3 \cdot 7 \mathrm{C}$ alloys.

\begin{tabular}{lccc}
\hline Sample & $\begin{array}{c}\text { Average } \\
\text { diameter } \\
(\mathrm{m})\left(\times 10^{6}\right)\end{array}$ & $\begin{array}{c}\text { Volume } \\
\text { fraction }\end{array}$ & $\begin{array}{c}\text { Surface area/vol. } \\
\left(\mathrm{m}^{2} / \mathrm{m}^{3}\right) \\
\left(\times 10^{-4}\right)\end{array}$ \\
\hline $\mathrm{Fe}-28 \cdot 1 \mathrm{Al}-2 \cdot 1 \mathrm{C}$ & 37 & $0 \cdot 15$ & $2 \cdot 4$ \\
$\mathrm{Fe}-27 \cdot 5 \mathrm{Al}-3 \cdot 7 \mathrm{C}$ & 42 & 0.25 & $3 \cdot 5$ \\
\hline
\end{tabular}

their average mean diameter were estimated by image analysis (table 2). Assuming that the carbide particles were spherical in shape, the number of particles per unit volume was also calculated. With the known number of second phase carbide particles, the surface area of carbide particles per unit volume was estimated (table 2). It is noticed that the size of the spherical carbide particles was approximately the same in both the specimens. As the $\mathrm{Fe}-27 \cdot 5 \mathrm{Al}-3 \cdot 7 \mathrm{C}$ alloy contained higher carbon than the $\mathrm{Fe}-28 \cdot 1 \mathrm{Al}-2 \cdot 1 \mathrm{C}$ alloy, it possessed a higher carbide volume fraction and surface area per volume of the spherical carbide particles.

After $2 \mathrm{~h}$ of exposure in the $0.05 \mathrm{~mol} / 1 \mathrm{H}_{2} \mathrm{SO}_{4}$ solution, the particle-matrix interfaces were the selective locations for corrosion (figure 5b). Deep corrosion pits at the carbide-matrix interfaces were observed in many locations after fairly long immersion times (figure $5 \mathrm{c}$ ). Interestingly, the carbide particles were not corroded with respect to the matrix as a function of time. This is reasonable as carbon is a relatively noble material and the carbide $\left(\mathrm{Fe}_{3} \mathrm{AlC}\right)$ contains a significant amount of carbon. The enhanced selective corrosion at the carbide-matrix interfaces could be because of the distance effect in galvanic corrosion (due to lower resistance near the interface). The matrix is expected to behave as the anode and carbide as the cathode in the local galvanic cells that form on the surface on immersion in the solution. Therefore, the matrix preferentially corrodes at the expense of the carbide, especially at the carbide-matrix interfaces. Interestingly, these selective dissolution sites can grow into deep pits with time, as has also been observed in the present study. Interestingly, the pits are potential sites for crack initiation by environmental degradation mechanism (stress corrosion cracking, hydrogen embrittlement, etc). It is therefore anticipated that the presence of carbides in the iron aluminide may not be beneficial for application of these intermetallics in immersion conditions, without the application of protective coatings.

\section{Conclusions}

The corrosion behaviour of two carbon-alloyed intermetallics of composition $\mathrm{Fe}-28 \cdot 1 \mathrm{Al}-2 \cdot 1 \mathrm{C}$ and $\mathrm{Fe}-$ $27 \cdot 5 \mathrm{Al}-3 \cdot 7 \mathrm{C}$ has been studied. Potentiodynamic polarization studies indicated that the intermetallics exhibited active-passive behaviour in an acidic solution $(0.05 \mathrm{~mol} / \mathrm{l}$ $\mathrm{H}_{2} \mathrm{SO}_{4}$ ) of $\mathrm{pH}=1$, whereas they exhibited stable passivity in a buffer solution $(0 \cdot 15 \mathrm{~N}$ boric acid $+0 \cdot 15 \mathrm{~N}$ $\mathrm{Na}_{2} \mathrm{~B}_{4} \mathrm{O}_{7} \cdot 10 \mathrm{H}_{2} \mathrm{O}$ ) of $\mathrm{pH}=8 \cdot 4$. Corrosion rates were also obtained by immersion testing, wherein it was observed that both the intermetallics exhibited similar behaviour. The corrosion rates increased in the initial stage and acquired a maximum, after which they decreased. In the final stages, the corrosion rate remained almost constant. This behaviour has been related with the potentiodynamic polarization behaviour. Microstructural study of the surfaces indicated that the carbon-alloyed intermetallics were susceptible to galvanic corrosion due to the presence of the carbides in the intermetallic matrix.

\section{Acknowledgements}

The authors thank Dr D Banerjee and Dr R G Baligdad, DMRL, Hyderabad, for providing the specimens used in the present study.

\section{References}

Babu N, Balasubramaniam R and Ramesh Kumar A V 2000 (to be published)

Baligdad R G, Prakash U, Ramakrishna Rao V, Rao P K and Ballal N B 1994 Iron \& Steel Making 21324

Baligdad R G, Prakash U, Radhakrishna A and Ramakrishna Rao V 1997a Scr. Mater. 36667

Baligdad R G, Prakash U, Radhakrishna A and Ramakrishna Rao V 1997b Scr. Mater. 36105

Jones D A 1992 Principles and prevention of corrosion (New York: Maxell Macmillan International)

Sen M and Balasubramaniam R 2000 Scr. Mater. (accepted) 